ENSAIO

Recebido em: 07/02/2017

Aceito em: 04/07/2017

\title{
0 acesso aberto à luz dos Estudos Sociais da Ciência e Tecnologia
}

\author{
Open access from the perspective of the Social Studies of \\ Science and Technology
}

\author{
Paulo Roberto CINTRA (paulocntr@yahoo.com)* \\ Ariadne Chloe FURNIVAL (chloe@ufscar.br)** \\ Douglas Henrique MILANEZ (douglasmilanez@yahoo.com)*** \\ * Doutorando do Programa de Pós-Graduação em Política Científica e Tecnológica - UNICAMP. \\ ** Professora do Departamento de Ciência da Informação - UFSCar. \\ *** Pesquisador do Departamento de Engenharia de Materiais - UFSCar.
}

\section{Resumo}

0 acesso aberto é um movimento em prol de uma literatura científica disponibilizada sem custos aos usuários e livre de restrições para seu reuso. Este ensaio tem por objetivo refletir sobre as mudanças trazidas pelo acesso aberto à comunicação científica à luz dos conceitos propostos pelos teóricos dos Estudos Sociais da Ciência e Tecnologia. Para tanto, o estudo se baseou nos imperativos institucionais de Merton, nos conceitos de Bourdieu sobre capital simbólico e nos argumentos de Latour acerca do arregimento de aliados. Concluiu-se que o acesso aberto tem potencial para alterar as disparidades hierárquicas existentes entre os pares, uma vez que possíveis ganhos em visibilidade, legibilidade e acessibilidade dos artigos disponibilizados em livre acesso, poderiam impactar positivamente na avaliação da produção do pesquisador junto às agências de fomento e instituições de ensino e, dessa forma, elevar seu capital científico.

Palavras-chave: Ciência. Comunicação Científica. Estudos Sociais da Ciência e Tecnologia. Acesso Aberto. Periódico Científico. Sociologia.

\begin{abstract}
Open access is a movement in favor of a scientific literature available without costs to users and free of restrictions for its reuse. This essay aims to reflect the changes brought by open access to scientific communication from the perspective of the concepts proposed by the Social Studies of Science and Technology theorists. Therefore, the study was based on Merton's institutional imperatives, Bourdieu's concepts of symbolic capital, and Latour's arguments about the recruitment of allies. It was concluded that open access has the potential to change the hierarchical disparities among peers, since possible gains in visibility, readability and accessibility of freely available articles could positively impact the evaluation of researcher's production within development agencies and Educational institutions and, in this way, increase their scientific capital.
\end{abstract}

Keywords: Science. Scientific Communication. Social Studies of Science and Technology. Open Access. Scientific Journal. Sociology.

v. 22 , n. $50,2017$. p. $205-222$

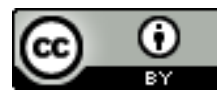




\section{INTRODUÇÃo}

Meadows (1999) afirma que a disseminação de informações é fundamental para o avanço e progresso da ciência, pois é dessa maneira que os conhecimentos gerados pelos cientistas podem ser avaliados, testados e certificados pelos pares, com seus resultados podendo ser aprovados ou refutados. Assim, esforços individuais de pesquisadores do passado e do presente são agregados a favor da produção científica futura. Merton (1997), um dos precursores dos Estudos Sociais da Ciência e Tecnologia, estabeleceu que um dos imperativos institucionais da ciência deveria ser o comunismo. Isto é, devido a sua dependência em relação à herança intelectual, todos os resultados científicos gerados devem ser comuns à sociedade. Logo, uma pressão é gerada sobre o cientista para que este divulgue os resultados de suas pesquisas, a fim de que as fronteiras do conhecimento possam evoluir.

Nesse sentido, van Raan (2001) mostra que a troca de informações pode ocorrer por meios formais e informais. A comunicação formal, por exemplo, se dá através da divulgação escrita, regida por normas, como em artigos de periódicos científicos e nos livros. Cristovão (1979) argumenta que esse tipo de comunicação oferece maior visibilidade, maior segurança quanto à recuperação da informação e maior controle na qualidade, já que, idealmente, nesse modelo de publicação, os trabalhos passam pelo crivo da revisão por pares. A comunicação informal, por sua vez, acontece quando a transmissão da informação ocorre em espaços de conversação, como conferências, eventos e seminários, além de contatos interpessoais e particulares como telefonemas, conversas, e-mails, redes sociais e visitas in loco (CRISTOVÃO, 1979). Para a autora, as vantagens nesse tipo de transferência de conhecimento são a maior atualização e agilidade no feedback acerca dos resultados produzidos entre os pares. Cristovão (1979) contudo, lembra que nesse tipo de comunicação não há uma avaliação prévia da informação, ou seja, não existem filtros que permitam chegar ao indivíduo apenas o conhecimento considerado de qualidade. Outrossim, a recuperação e armazenagem de tais conversas são mais difíceis quando comparadas às da comunicação formal, visto que, nesses casos, a informação é mutável e, portanto, passível de alterações em curtíssimo espaço de tempo. Assim, a comunicação informal, mesmo que por ventura seja armazenada, não fica disponível para ampla divulgação.

Por essa acepção, segundo Mueller (2006), o principal canal de comunicação entre os pares são os periódicos, pois, além das características apontadas por Cristovão (1979), ainda possibilitam confirmar autoria de uma descoberta científica. Suber (2012), no entanto, observa a existência de diversas barreiras de acesso a esta informação científica divulgada através dos periódicos, sobretudo pelo progressivo aumento no custo de assinatura das principais revistas científicas, fato que acarretou em um movimento em prol do acesso aberto. Termo advindo do inglês open access, o acesso aberto foi definido pela Iniciativa Budapeste para o Acesso Aberto (Budapest Open Access Initiative), em 2002, como a disponibilização online de artigos científicos em texto completo aos usuários interessados em seu conteúdo, sem custos ou limitações de acesso, e sem restrições de direitos autorais ou de licenciamento para seu reuso. A Budapest Open Access Initiative (2002) ainda ratificou duas formas de se disponibilizar os arquivos em acesso aberto: i) pela "via verde" (green road), na qual os autores realizam o autoarquivamento de suas pesquisas em repositórios institucionais e sites pessoais; e ii) pela "via dourada" (gold road), em que as editoras dos periódicos asseguram o livre acesso às suas publicações. Weitzel (2014) aponta também a existência de um modelo "híbrido", pelo qual as revistas científicas de acesso fechado (ou seja, aquelas cujo acesso ocorre através da subscrição do periódico) oferecem a opção aos autores de fazerem 
a publicação de seus artigos imediatamente em acesso aberto, através do pagamento de taxas de processamento de artigos (article processing charges - APCs).

Considerando que no modelo atual de avaliação científica, o impacto de uma pesquisa costuma ser ponderado pela quantidade total de citações que o trabalho recebe, iniciou-se no meio acadêmico uma discussão na qual questiona-se se artigos de acesso livre a qualquer usuário seriam mais citados do que aqueles em acesso restrito. Essa hipótese, conhecida por Open Access Citation Advantage (OACA), argumenta que a facilidade de acesso a esses documentos pode facultar maior visibilidade às publicações e, consequentemente, favorecer uma potencial obtenção de mais citações. Conforme Droescher e Silva (2015), apesar de não existir ainda um consenso a esse respeito, a hipótese de OACA já foi testada para diversas áreas da ciência, indicando que o acesso aberto pode elevar o número de leitores dos artigos, ao acrescentar usuários que não teriam outra forma de acessá-los e, dessa forma, aumentar potencialmente o impacto de um trabalho científico.

A partir deste contexto, o objetivo do presente ensaio é refletir sobre as mudanças trazidas pelo acesso aberto à comunicação científica à luz dos conceitos trazidos pelos teóricos dos Estudos Sociais da Ciência e Tecnologia. Para tanto, dividiu-se o estudo da seguinte maneira: nesta primeira seção foram apresentados conceitos introdutórios acerca do tema e o objetivo proposto. Na segunda e terceira seção são discutidas, respectivamente, as origens da sociologia da ciência e do acesso aberto. A quarta seção explora a importância das citações dentro da comunidade científica e as vantagens oferecidas pelo acesso aberto nesse sentido. Por fim, a quinta seção expõe as considerações finais nas quais busca-se refletir acerca da abordagem dos Estudo Sociais da Ciência e Tecnologia sobre o acesso aberto.

\section{ESTUDOS SOCIAIS DA CIÊNCIA E TECNOLOGIA}

De acordo com Spiegel-Rösing (1977), os Estudos Sociais da Ciência e Tecnologia (ESCT) surgiram a partir da Segunda Guerra Mundial, momento no qual observaram-se alterações nas relações entre a ciência e os poderes militar, econômico e político. Segundo a autora, essas mudanças se deram, por exemplo, através de massivo apoio financeiro governamental à ciência, que, além de contribuir para um crescimento quantitativo da produção científica à época, também possibilitaram a realização da Big Science, ou seja, dos projetos de grande porte, intensivos em capital e que demandavam uma estrutura organizacional igualmente desenvolvida, como o caso do Projeto Apollo, que levou o homem à lua.

Moreira e Velho (2008) explicam que o auxílio governamental à ciência é resultado das primeiras políticas de ciência e tecnologia que despontaram no período pós-guerra, advindas sobretudo dos Estados Unidos, e que tentavam esboçar o papel da ciência em tempos de paz, além de dispor sobre sua utilidade à sociedade e interdependência com a tecnologia. Conforme Godin (2006), o relatório Science: the Endless Frontier ${ }^{1}$, elaborado por Vannevar Bush, foi a primeira defesa mais enfática de que a destinação de investimentos à produção de novos conhecimentos científicos (pesquisa básica) levariam ao desenvolvimento tecnológico (pesquisa aplicada) e, consequentemente, conduziriam ao progresso socioeconômico, uma vez que haveria a disponibilidade de bens e serviços mais modernos à sociedade. Segundo o autor, este veio a ser conhecido como o "modelo linear de inovação" e teve bastante influência ao longo de muitas décadas, servindo como base teórica para que organizações acadêmicas e consultores especialistas

${ }^{1}$ Ciência, a Fronteira sem Fim. 
pudessem justificar a necessidade de apoio governamental ao desenvolvimento científico e tecnológico em diversos países.

Para Stokes (2005), contudo, a segmentação rigorosa da ciência entre pesquisa básica e pesquisa aplicada não ocorre de modo tão alinhado conforme defendia Bush. Em contraponto, o autor indica que a análise do desenvolvimento científico pode ser interpretada através de um modelo mais dinâmico, pelo qual ciência e tecnologia interagem com uma influenciando reciprocamente os rumos tomados pela outra. Rosenberg (2006, p.218) concorda que a tecnologia não deve ser vista apenas como uma simples consequência da pesquisa básica ou "como mera aplicação do conhecimento científico preexistente". Para o autor, a tecnologia deve ser encarada como uma forma própria de conhecimento científico, que foi, de modo empírico, sendo adquirido e acumulado ao longo do tempo, podendo, em alguns casos, até mesmo preceder a pesquisa básica. Sem embargo, Stokes (2005, p.48-49) compreende que

\begin{abstract}
Ainda que a visão da ciência e da tecnologia articulada por Bush após a guerra esteja longe de ser universalmente aceita, ela permeou de tal maneira o pensamento sobre a atividade científica que acabou por constituir-se num paradigma para o entendimento da ciência com a tecnologia no final do século XX.
\end{abstract}

Nada obstante, segundo Spiegel-Rösing (1977), os mesmos avanços observados com a Big Science também trouxeram uma série de questionamentos no que diz respeito aos caminhos dados à ciência e tecnologia. Houve uma desilusão generalizada sobre a real utilidade e propósito das pesquisas que estavam sendo feitas, uma vez que se verificavam evidentes degradações ao meio ambiente e permaneciam sem solução diversos problemas sociais, como tráfico e abuso de drogas, criminalidade juvenil e urbanização precária. De acordo com a autora, a combinação desses fatores levou a uma reorientação de prioridades, de forma que o desenvolvimento da ciência e tecnologia respondesse mais enfaticamente às questões sociais. Em suma,
Se a guerra, a conveniência econômica e o poder político são condições essenciais na origem e no desenvolvimento institucional precoce do campo dos ESCT, então a má direção da ciência e da tecnologia e a consequente desilusão generalizada sobre sua utilidade incondicional e desejável, são ingredientes importantes para o seu desenvolvimento recente (SPIEGEL- RÖSING, 1977, p.8, tradução nossa).

Por essa perspectiva, Spiegel-Rösing (1977) afirma que a pesquisa no campo dos ESCT sempre se justificou através da promessa de solução para os problemas científicos e tecnológicos. Nesse sentido, segundo Mueller (2006), compreender em qual contexto os cientistas atuam e se relacionam é fundamental para entender como essa coletividade se comporta dentro da sociedade.

Conforme Barnes e Dolby (1970), o sociólogo Robert Merton foi um dos pioneiros desses estudos, tendo começado a escrever sobre o assunto entre o final da década de 1930 e começo dos anos 1940. Merton (1997) defendia a tese de que a ciência sofre com a influência de agentes externos e de interesses particulares, sendo necessária a existência de um ethos científico, ou seja, um complexo de normas e valores que serviria como guia para o comportamento do cientista, podendo o pesquisador estar sujeito a sanções caso as descumprisse. Assim, Merton (1997) buscava identificar e estabelecer essas normas e valores, que, embora não estivessem escritos em lugar algum, seriam imperativos que poderiam ser inferidos a partir do consenso moral da comunidade científica. Por essa acepção, o autor descreve que o ethos da ciência moderna é composto por quatro imperativos 
institucionais: i) universalismo: independente de raça, gênero, nacionalidade, religião, classe e qualidades ou atributos pessoais, as pesquisas de quaisquer origens deveriam ser analisadas de modo impessoal; ii) ceticismo organizado: pode ser considerado como o princípio da revisão por pares, na qual todos os estudos devem ser submetidos ao escrutínio da comunidade cientifica, sendo testadas de modo imparcial; iii) comunismo: dado que as propriedades das descobertas científicas são produto da colaboração entre os pesquisadores, seus resultados devem também ser comuns à comunidade; e iv) desinteresse: elemento básico da ciência, pelo qual os cientistas não devem agir por interesses próprios, mas pelo avanço do seu campo de conhecimento.

Segundo Vessuri (1991), o pensamento de Merton teve grande influência nos ESCT até os anos 1970. De acordo com a autora, a partir desta década, porém, a hegemonia da linha de pensamento mertoniana passou a dar espaço a outras escolas, como a do Construtivismo Social. Conforme Moreira e Velho (2008), essa alternativa de análise sociológica se baseia na ideia de que, diferente da proposição quase utópica formulada por Merton, na realidade, o que se observa é que outros atores não-científicos, como empresas, indústrias, agências de fomento, governo e sociedade, também participam da construção do processo de produção e avaliação do conhecimento. Conforme Mueller (2006, p.31):

A comunidade científica não existe em um vácuo social, mas é um dos muitos grupos sociais que compõem a sociedade contemporânea, estando, portanto, sujeita às forças presentes nessa sociedade. Assim, permeando e influenciando a estrutura de seu intrincado sistema de comunicação, há interesses financeiros das editoras que dominam o mercado de periódicos, há os interesses das instituições de pesquisa e universidades que lutam por prestígio e financiamento, há interesses nacionais, políticos e econômicos que buscam o desenvolvimento e prestígio nacional e há o interesse pessoal dos pesquisadores, tanto daqueles que já ocupam os lugares mais altos na hierarquia - e que desejam lá permanecer -, quanto daqueles que estão em ascensão e disputam lugares mais altos e também os marginalizados, para quem mudanças seriam, talvez, favoráveis.

O conceito de Bourdieu (1976) sobre o campo cientifico trata exatamente das relações de disputa e influência entre esses diversos atores. Identificado como um sistema de forças, os cientistas disputam ganhos de capital científico, ao mesmo tempo em que defendem posições previamente conquistadas. Conforme Bourdieu (2004), a posição de um cientista dentro do campo dependerá da sua disponibilidade de capital científico, ou seja, do capital simbólico determinado pela competência do pesquisador em tratar sobre um assunto com propriedade e autoridade e que se estabelece através da detenção de recompensas, que são ofereidas na forma de prestígio, celebridade e reconhecimento pela comunidade acadêmica. Portanto,

A estrutura do campo, definida pela distribuição desigual do capital, ou seja, das armas ou dos trunfos específicos, faz-se sentir, não por interação direta, intervenção ou manipulação, sobre todos os agentes, mas regulando as possibilidades que lhes estão abertas conforme estejam pior ou melhor situados no campo, ou seja, nessa distribuição. O dominante é aquele que ocupa na estrutura uma posição tal que a estrutura age em seu favor (BOURDIEU, 2008, p.53).

Assim, para Bourdieu (1976), o campo científico é também um local de disputas políticas, onde a posição que cada pesquisador ocupa dentro da hierarquia 
é definida pela quantidade de capital científico acumulado e que traz implicações na definição de quais serão seus problemas de pesquisa, suas metodologias e estratégias científicas adotadas. Logo, segundo o autor, não existem escolhas científicas, pois todos os passos dados por um cientista fazem parte de uma estratégia política que visa abstrair o maior lucro científico possível. Mesmo "o interesse 'puro', desinteressado, é um interesse pelo desinteresse, forma de interesse que convém a todas as economias dos bens simbólicos, economias antieconômicas, nas quais, de alguma maneira, é o desinteresse que 'compensa'" (BOURDIEU, 2004, p.31).

Conforme Bourdieu (2004), os dominantes detêm a autoridade para definir as regras do jogo e determinar como serão alocados as futuras recompensas. Gläser e Laudel (2007), por exemplo, consideram que pesquisadores que possuem todas as ferramentas e softwares a sua disposição e tem acesso aos dados provenientes de bases pagas, adquirem uma vantagem na realização de estudos mais completos e complexos, pois, assim, inviabilizam a replicação dos resultados pelos demais colegas da área desprovidos de tais recursos. Dessa forma, tais pesquisadores garantem a manutenção de seus status dentro da hierarquia do campo e, ao mesmo tempo, dificultam aos demais pares a aferição desses benefícios.

Latour e Woolgar (1997), por sua vez, discutem que as recompensas no campo científico podem ser qualificadas entre dois tipos: crédito-reconhecimento e crédito-credibilidade. No primeiro caso, o sistema de recompensas gratifica o cientista pelos resultados de sua obra e por sua capacidade de fazer ciência. É "o reconhecimento, pelos pares, de uma obra científica passada" (LATOUR; WOOLGAR, 1997, p.220). 0 segundo tipo de crédito diz respeito à própria essência dos fatos, ao conteúdo da produção científica e à influência do pesquisador em relação a fatores externos, como instituições e financiamentos. De acordo com os autores, os créditos científicos são como mercadorias intercambiáveis, que podem ser divididas ou compartilhadas, acumuladas, desperdiçadas e, mesmo, roubadas. Assim, as negociações entre os cientistas ocorrem no sentido de obterem ganhos de credibilidade, que permitirão o seu reinvestimento e, consequentemente, possibilitarão novos ganhos futuramente.

Sobre esse ponto, Merton (1968) tece algumas reflexões sobre o que chamou de Efeito Mateus (The Matthew Effect in Science). Em referência a passagem do texto bíblico $^{2}$, a ideia deste efeito está centrada no fato de que cientistas que já possuem uma reputação considerável tendem a receber mais recompensas que seus colegas, seja através de maiores ganhos em visibilidade e na facilidade de obtenção de recursos às suas pesquisas, seja na conquista de prêmios científicos, ou ainda por meio de um maior número de citações aos seus artigos. 0 autor elenca certos atributos que elevam o nível de reconhecimento que um cientista obtém com o seu trabalho. São eles: a reputação da instituição onde o pesquisador atua, se sua carreira teve um início precoce ou tardio e se já possui uma quantidade mínima de artigos e outros trabalhos publicados que garantam estabilidade para obtenção de novos financiamentos e publicações. Portanto, constata-se que uma avaliação positiva acerca de suas pesquisas pode ser importante para o reconhecimento e a garantia de recompensas futuras. Dessa maneira, a produção e, principalmente, as formas em que ocorrerá a divulgação dos resultados de seus estudos parecem ser relevantes na carreira do cientista, havendo, teoricamente, uma preocupação em ampliar a disseminação de seus resultados.

2 "Pois a quem tem, mais será dado, e terá em grande quantidade. Mas a quem não tem, até o que tem lhe será tirado" (BÍBLIA, Mateus, 25:29). 


\section{ACESSO ABERTO}

Para se compreender como se deu a origem do movimento do acesso aberto, é preciso verificar a conjuntura na qual pesquisadores, bibliotecas e editoras estavam inseridos (MUELLER, 2006). Nesse sentido, de acordo com a autora, desde as décadas de 1970 e 80 , as bibliotecas públicas de diversos países começaram a ter dificuldades em manter seus acervos atualizados, pois os valores pedidos pelas editoras para renovação das assinaturas das coleções dos periódicos aumentaram além da inflação da época. Tzoc (2012) mostra que, entre 1986 e 2004, o valor despendido pelas bibliotecas dos Estados Unidos para subscrição dos periódicos subiu aproximadamente $273 \%$. Segundo o autor, durante esse mesmo período, a taxa de inflação foi de $73 \%$, fato que evidencia a disparidade na elevação dos custos para se acessar o conteúdo das revistas científicas. Mueller (2006) acrescenta que a crescente demanda de informação pelos usuários das bibliotecas, aliada à falta de financiamento que viabilizasse a subscrição das revistas científicas, conduziram ao estouro da chamada "crise dos periódicos", levando um número cada vez maior de bibliotecas a cancelar as assinaturas dessas publicações.

Segundo Rodrigues (2004), para contornar e evitar prejuízos advindos desse ambiente de crise, as grandes editoras começaram a negociar com os centros de informação por meio da adoção de uma nova estratégia de vendas, pela qual as bibliotecas, ou um consórcio de bibliotecas, realizava a compra conjunta de uma grande parcela dos títulos publicados pela editora, por um custo mais acessível. Em outras palavras, as vendas eram feitas "em pacote", de tal modo que as editoras buscavam manter o mesmo volume de vendas, ao passo que as bibliotecas garantiam acesso a um maior número de periódicos aos seus usuários. Para Gumieiro e Costa (2012), mesmo com a possibilidade de compra de periódicos "em pacote", o advento da internet e o surgimento dos periódicos eletrônicos a partir dos anos 1990, criaram a expectativa no meio acadêmico de maior acesso aos conteúdos das publicações científicas, quando comparadas com aquelas de formato exclusivamente impresso. De acordo com Mueller (2006, p.27), observou-se o estabelecimento de uma esperança utópica, "no qual o acesso a todo conhecimento científico se tornaria universal e sem barreiras". Para a autora, essa perspectiva era ainda mais ambicionada pelos países cientificamente periféricos, que esperavam obter maior visibilidade de sua produção local ante a comunidade científica internacional.

Gumieiro e Costa (2012), entretanto, relatam que essa expectativa não se tornou realidade, haja vista a manutenção dos preços para subscrição dos periódicos, tanto das versões eletrônicas, quanto das impressas. Conforme Suber (2012), os custos para aquisição dos artigos permanecem como uma das principais barreiras de acesso à informação, pois, embora a compra de um único artigo possa até ser possível por um pesquisador, na maioria dos casos é preciso ler centenas de outros trabalhos para se realizar uma única pesquisa científica e a obtenção particular desse número de artigos torna-se inexequível.

Em resposta a esta conjuntura de acesso restrito às informações científicas, Mueller (2006) e Rodrigues (2004) apontam que teve início no meio acadêmico e entre os profissionais da ciência da informação, a busca por alternativas que pudessem contornar essas dificuldades. Entre as primeiras soluções propostas, estavam a divulgação e armazenamento de pre-prints em repositórios eletrônicos. A partir desse interesse por meios de difusão da ciência mais amplos, Rodrigues (2004) menciona a existência de alguns projetos que aparecem entre as bases do movimento em prol do acesso aberto, como o lançamento do Fórum da American Scientist, o início da Declaração de Independência por algumas revistas e a criação da 
Scholarly Publishing and Academic Resources Coalition (SPARC), pela Association of Research Libraries (ARL). Além disso, Tzoc (2012) destaca a ocorrência de três eventos que auxiliaram no estabelecimento e na consolidação do movimento dentro da comunidade acadêmica: a Iniciativa Budapeste para o Acesso Aberto (Budapest Open Access Initiative), a Declaração de Bethesda (Bethesda Statement on Open Access Publishing) e a Declaração de Berlim sobre o Livre Acesso ao Conhecimento (Berlin Declaration on Open Access to Knowledge in the Sciences and Humanities). Esses eventos permitiram que cientistas e pesquisadores fossem encorajados a buscar e contribuir para um acesso universal e irrestrito ao conhecimento científico produzido. Para Mueller (2006, p.27), "[o] movimento para acesso livre ao conhecimento científico pode ser considerado como o fato mais interessante e talvez importante de nossa época no que se refere à comunicação científica".

Dentre as ações citadas, a Budapest Open Access Initiative é considerada uma das mais importantes pela literatura, pois foi onde o termo 'acesso aberto' foi conceituado. Realizada em Budapeste, na Hungria, pela Open Society Foundations (OSF), em dezembro de 2001, a Iniciativa Budapeste para o Acesso Aberto apontou que a internet e a boa vontade dos cientistas em publicarem os resultados de suas pesquisas tornaram possível a origem de um novo bem público sem precedentes, um modelo de transmissão de comunicação científica de acesso irrestrito e sem custos aos leitores. Assim, conforme definição da Budapest Open Access Initiative (2002):

\begin{abstract}
Por "acesso aberto" a esta literatura, nos referimos à sua disponibilidade gratuita na internet, permitindo a qualquer usuário a ler, baixar, copiar, distribuir, imprimir, buscar ou usar desta literatura com qualquer propósito legal, sem nenhuma barreira financeira, legal ou técnica que não o simples acesso à internet. A única limitação quanto à reprodução e distribuição, e o único papel do copyright neste domínio é o controle por parte dos autores sobre a integridade de seu trabalho e o direito de ser propriamente reconhecido e citado.
\end{abstract}

Na Budapest Open Access Initiative foram ainda recomendadas as duas principais estratégias para o acesso aberto3: através da "via dourada" (golden road), na qual as próprias editoras dos periódicos garantem o acesso livre ao conteúdo de suas edições; e pela "via verde" (green road), que ocorre quando os autores depositam seus artigos em repositórios digitais abertos ao público. Craig et al. (2007) explicam que na via dourada a publicação ocorre de modo semelhante a dos periódicos tradicionais, com a diferença de que os leitores não precisam pagar uma taxa de subscrição para acesso aos artigos. Dessa forma, garante-se o livre acesso a qualquer pessoa que tenha interesse na pesquisa, sem que usuários, bibliotecas ou centros de informação precisem arcar com os custos para aquisição daquele conteúdo.

Por outro lado, Craig et al. (2007) esclarecem que, na via verde, cópias dos artigos podem ser depositadas pelos cientistas tanto em repositórios digitais ligados às instituições onde atuam, como em sites e blogs pessoais sem caráter comercial, ou em redes sociais acadêmicas, como o ResearchGate. Sobre essa estratégia, Harnad (2006) discute a existência da Zeno's Paralysis, denominação para um conjunto de obstáculos psicológicos que impedem os pesquisadores de fazerem o arquivamento de seus artigos. Um desses obstáculos, por exemplo, é o da fobia da pirataria, isto é, o receio dos cientistas de que o autoarquivamento da versão pre-print do manuscrito submetido possa infringir alguma das restrições dos acordos de transferência de

3 Para descrição de outros modelos de negócio adotados no contexto do acesso aberto, ver Kuramoto (2006). 
direitos autorais (copyright transfer agreements - CTAs), pelos quais os pesquisadores entregam às editoras dos periódicos os seus direitos sobre o artigo. Para dirimir essas questões, o autor lembra que, em muitos casos, as próprias editoras permitem aos cientistas a realização desse arquivamento.

Assim, dependendo das políticas de acesso aberto de cada periódico, podem ser autorizados o autoarquivamento das versões pre-print (arquivos cujos conteúdos ainda não passaram pelo peer-review), das versões post-print (textos após a revisão por pares) ou, ainda, das versões finais dos artigos (documentos já com a diagramação padrão da revista). Nesses casos, porém, deve-se atentar para a exigência de um período de carência (embargo) entre a data de publicação do artigo no periódico e seu depósito nos repositórios institucionais. Além dos sites das revistas, uma fonte alternativa para se buscar informações relativas às condições e permissões das políticas de acesso aberto dos periódicos é através da base SHERPA/RoMEO, que coleta e compila esses dados a partir dos próprios CTAs emitidos pelas editoras.

Além dessas duas estratégias, um modelo híbrido vem sendo recorrentemente utilizado pelas revistas científica. Conforme Weitzel (2014, p.67), por esse modelo, "o acesso imediato à produção científica [...] seria garantido pelos autores ou instituições produtoras por meio de pagamento de taxas de processamento dos artigos (Article Processing Charge - APC) aos editores comerciais que publicam os periódicos". Ou seja, após o manuscrito passar pela revisão por pares e ter o aceite para publicação, é oferecido ao autor a opção do pagamento do APC para a publicação do artigo em acesso aberto diretamente no site do periódico. Dessa forma, a cobrança de subscrição dos periódicos é mantida, ao mesmo tempo em que se possibilita aos autores oferecerem acesso livre e imediato aos resultados de suas pesquisas.

Pinfield, Salter e Bath (2015), entretanto, chamam a atenção para o risco de existir uma dupla-cobrança (double-dipping), já que podem existir situações nas quais as editoras lucram duas vezes, a partir de um único conteúdo. Isto é, como geralmente são os órgãos de fomento e as instituições de ensino os responsáveis pelo dispêndio em ambos os casos, as editoras acabam auferindo lucro duas vezes sobre um mesmo cliente: primeiro pelo recebimento dos APCs e, posteriormente, pela subscrição para o acesso ao conteúdo completo dos periódicos. Kuramoto (2006, p.92) resume a situação da seguinte forma,

Do ponto de vista ético, os resultados dessas pesquisas deveriam ser de livre acesso. Não é isso, entretanto, o que acontece no sistema de comunicação científica tradicional. 0 pesquisador ou qualquer outro cidadão, para ter acesso àquilo que foi produzido com o apoio do Estado, precisará pagar pela assinatura de uma publicação científica. Trata-se de uma situação paradoxal, pois o Estado, para promover o acesso àquilo que produz, é obrigado a arcar com os custos de manutenção das coleções das revistas em que são publicados os resultados de sua produção científica. [...] Os autores nada recebem pelas publicações de seus trabalhos, tendo muitas vezes de pagar para ver os seus trabalhos publicados. Portanto, os autores não se interessam pelo retorno financeiro obtidos pela publicação de seus trabalhos, mas pelo prestígio e notoriedade que essas publicações podem lhes trazer. 0 peso desse prestígio é sentido no momento em que esses pesquisadores submetem um projeto ou pedido de auxílio junto às agências de fomento, ou mesmo no seu próprio ambiente de trabalho, quando de sua avaliação de desempenho.

Assim, conforme a Budapest Open Access Initiative (2002), o acesso aberto oferece aos leitores "um potencial extraordinário no que se refere à difusão e 
aproveitamento da literatura relevante, conferindo aos seus autores e obras grande visibilidade, legibilidade e impacto". Na passagem, Kuramoto (2006) indica que o interesse dos pesquisadores em publicar os resultados de suas pesquisas está relacionado à possibilidade de ganhos em "prestígio e notoriedade". Ademais, Meadows (1999, p.89) aponta que "uma forma de avaliar a qualidade de uma publicação consiste em verificar o nível de interesse dos outros pela pesquisa". Nesse sentido, a próxima seção discute as razões pelas quais a citação tem grande importância no sistema de avaliação da produção científica e as suas críticas subsequentes.

\section{AS CITAÇõES NO CAMPO CIENTÍFICO}

Van Raan (2001) discute que os cientistas possuem uma dupla função no campo científico, pois são, ao mesmo tempo, autores e leitores de trabalhos acadêmicos. Em outras palavras, são receptores das informações científicas transmitidas pelos pares e, concomitantemente, são responsáveis pela disseminação dos conhecimentos científicos à sociedade. Essa dicotomia tem dois efeitos antinômicos: como autor, o cientista quer ampliar sua produção e publicar o máximo possível de artigos; e como leitor, quer manter sua leitura ao mínimo, haja vista que o tempo despendido nessa tarefa precisa ser otimizado pela leitura de publicações que realmente sejam relevantes para o seu estudo. Priem, Groth e Taraborelli (2012) corroboram com a ideia de que o volume crescente de conhecimento produzido levou cientistas e agências de fomento a criarem filtros para melhor alocar o tempo e os recursos limitados. Os autores citam que, a princípio, esta seleção era realizada manualmente, com a leitura individual dos trabalhos acadêmicos submetidos, mas lembram que, em meados do século XX, tal solução se tornou inviável em função da quantidade de informação disponível. Por essa razão, filtros baseados em indicadores bibliométricos, em especial aqueles centrados no número de citações, surgiram como um método para contornar o problema, pois permitiram automatizar o processo de seleção, ao tomar como base o próprio reconhecimento realizado pelos pares.

Conforme Rodrigues (1982), as citações dizem respeito ao conjunto de referências que compõem uma publicação e podem ser utilizadas para se especificar a teoria ou método utilizado na pesquisa, para reconhecer a existência ou fazer elucidações acerca de outros estudos da mesma natureza temática, para se apoiar ou refutar outros artigos ou, ainda, para indicar que a pesquisa é uma construção alternativa à proposta do trabalho citado. Além disso, segundo a autora, as citações podem servir como instrumentos de recuperação da informação científica, oferecendo reconhecimento e direitos de propriedade a quem é devido. De acordo com Lima, Velho e Faria (2012), a citação é vista pelos Estudos Sociais da Ciência e Tecnologia como a forma pela qual o comportamento social da comunidade científica pode ser representado, uma vez que as citações conseguem evidenciar as relações existentes entre autores, instituições e grupos de pesquisa dentro do campo científico.

Para Latour (2011), por exemplo, a escrita e publicação dos artigos tem por objetivo persuadir e convencer os pares de que os resultados ali apresentados são verdadeiros e que devem ser utilizados posteriormente. Nesse sentido, o autor mostra que os cientistas precisam recrutar aliados, atores humanos (como professores, estudantes, autores do passado e pessoas de organizações públicas ou privadas) e não-humanos (por exemplo, máquinas, equipamentos, objetos da pesquisa, periódicos e repositórios digitais) que contribuirão para o sucesso desta empreitada. Assim, um dos primeiros arregimentos realizados pelos pesquisadores ocorre através de citações a textos anteriores. Isto é, busca-se na literatura 
pregressa o máximo de referências que possam contribuir para o fortalecimento das ideias que desejam ser transmitidas. Posteriormente, com a finalização da pesquisa e a publicação dos resultados dela advindos, é também preciso que o trabalho seja tomado como uma referência positiva pela próxima geração de textos.

Por essa acepção, Latour e Woolgar (1997) discutem que transformar enunciados em fatos adquiridos faz parte de um processo socialmente construído, pelo qual os cientistas se utilizam de modalidades positivas e negativas para dirimir controvérsias. Para os autores, os enunciados referem-se às afirmações proferidas pelos cientistas e pesquisadores por meio da publicação de artigos, apresentações em congressos ou através de conversas informais. Segundo Latour (2011), as modalidades podem ser compreendidas como assertivas ulteriores que determinam os status dos enunciados, ou seja, são as citações realizadas pelos pesquisadores acerca dos trabalhos de seus pares. Assim, as modalidades positivas dizem respeito às sentenças que fortalecem os enunciados, impulsionando a ideia original e levando-as para longe do momento em que foram produzidas. Enquanto que as modalidades negativas são as declarações que levam os enunciados em direção às condições de sua produção, pois rebaixam ou confrontam o que havia sido declarado anteriormente e colocam em dúvida a veracidade dos fatos ali apresentados. Assim, o uso de modalidades (ou citações) permite que "uma sentença possa ser tornada mais fato ou mais ficção, dependendo da maneira como está inserida em outras" (LATOUR, 2011, p.45). Sismondo (2011, p.37, tradução nossa) concorda que "o artigo científico geralmente é um argumento. Suas citações, portanto, são veículos para promover seu argumento ".

Conforme Mueller (1999), o número de citações que um artigo recebe pode ser considerado um indicador de reconhecimento da influência de um cientista. Segundo a autora, os potenciais ganhos de prestígio dentro da comunidade científica representam uma das motivações mais eficientes para que os pesquisadores publiquem. Nas palavras de Bourdieu (2004, p.26),

"o capital científico é uma espécie particular do capital simbólico (o qual, sabe-se, é sempre fundado sobre atos de conhecimento e reconhecimento) que consiste no reconhecimento (ou no crédito) atribuído pelo conjunto de pares-concorrentes no interior do campo científico".

Nesse sentido, Swan (2010) aponta a existência de uma discussão dentro da comunidade científica na qual sugere-se que, em função das vantagens descritas pela Budapest Open Access Initiative, o acesso aberto poderia aumentar o número de citações recebidas pelos artigos disponibilizados em livre acesso aos leitores, já que permitiria que os resultados dessas pesquisas também chegassem aos pesquisadores que não possuem condições para acessá-los. Conhecida por Open Access Citation Advantage (vantagens de citações do acesso aberto), essa hipótese indica que o impacto alcançado por um artigo em acesso aberto seria maior em comparação com aqueles disponibilizados exclusivamente em acesso fechado. Segundo Mueller (1999, online) "para ser lido e citado, um artigo precisa ser encontrado pelo leitor".

Conforme mostra Swan (2010) e Droescher e Silva (2015), diversas pesquisas já foram realizadas com o objetivo de investigar se o acesso aberto proporciona de fato uma vantagem de citação. Além do trabalho prógono de Lawrence (2001) para o campo da Ciência da Computação, as autoras sinalizam a existência de estudos para as áreas de Engenharias (ANTELMAN, 2004), das Ciências Naturais (HARNAD; BRODY, 2004) e mesmo das Ciências Sociais e Humanas (ATCHINSON; BULL, 2015). Embora algumas dessas pesquisas não tenham apresentado vantagens significativas para determinados campos, como da Economia (FRANDSEN, 2009), parcela significativa comprova que o acesso aberto 
parece contribuir para um aumento potencial do número de citações. Sobre esse ponto, Swan (2010, p.1-2, tradução nossa) ressalta que,

Certamente não houve, mesmo no início, uma expectativa entre os pensadores sobre este tema que o acesso aberto poderia trabalhar magicamente e fazer o incitável de repente citável. As citações repousam sobre a qualidade, relevância, originalidade e influência do trabalho. Relatórios de pesquisa que acrescentam pouco ou nada ao desenvolvimento ou pensamento em um campo ganham pouca ou nenhuma atenção de outros pesquisadores, mesmo que possam ser facilmente acessados. [...] Em outras palavras, a expectativa era que essa literatura até então inacessível fosse tão variada em sua utilidade e influência quanto sua contrapartida na literatura de assinatura já acessível. Alguns artigos se provariam ser citáveis; outros não. Que o acesso aberto iria produzir um aumento de citação automática para cada artigo nunca foi a expectativa. Havia, no entanto, a expectativa de que o acesso aberto elevaria o nível de leitores e proporcionaria, quando merecido, um aumento da citação resultante, como se todas as bibliotecas acadêmicas do mundo subitamente e exuberantemente subscrevessem toda a literatura acadêmica mundial.

Harnad e Brody (2004) concordam que ter acesso ao conteúdo científico produzido pelos pares é importante para haver a citação, mas ressaltam que não se trata de uma condição exclusiva. Com o propósito de identificar quais os outros motivos explicam essa potencial vantagem de citações proporcionada pelo acesso aberto, Harnad (2005) indica a existência de fatores que são temporários e outros que são permanentes. Entre os temporários, o autor aponta a vantagem competitiva, o viés de qualidade e a vantagem de disseminação do arXiv, ou seja, os pesquisadores estão mais propensos a fazer o autoarquivamento e a disponibilizarem em acesso aberto os artigos que eles próprios consideram como sendo de melhor qualidade. Além disso, averiguou que, em alguns casos, como para a área da Física, pre-prints depositados na plataforma do arXiv tem vantagens sobre aqueles que não o são. Dentre os fatores permanentes, Harnad (2005) cita a vantagem de antecipação, isto é, as pesquisas que são disponibilizadas em acesso aberto desde o estágio do pre-print possuem vantagem em relação àquelas autoarquivadas posteriormente, já que as citações também podem ocorrer antecipadamente. Ademais, de acordo com o autor, existem ainda vantagens de qualidade e de uso, isto é, artigos que realmente são de alta qualidade e possuem um grande número de downloads tem vantagem quando comparados com os demais, pois aqui não é apenas o cientista quem julga positivamente o valor de seu trabalho, mas também os pares. Harnad (2005) salienta, por fim, que alguns desses fatores tem caráter temporário porque suas vantagens desaparecem no momento em que os pesquisadores fazem o autoarquivamento de todas as suas publicações.

Sobre a vantagem de uso verificada por Harnad (2005), Freitas (1997) argumenta que existem pesquisadores que realizam citações a autores já consagrados na literatura visando apenas dar maior autoridade e credibilidade ao referencial teórico de sua pesquisa e, consequentemente, ao seu próprio artigo. Esse apontamento faz parte das críticas que a avaliação da produção científica baseada no número de citações recebe na literatura e que podem acabar alterando o real impacto de uma publicação ou de um autor. Priem, Groth e Taraborelli (2012) discutem, por exemplo, que podem ocorrer casos em que os créditos (as citações) não são dados aos autores originais, através da "não citação" ou pela citação da citação. Freitas (1997, p.124) explica melhor esse último ponto, ao mostrar que, "embora A tenha influenciado C, foi B quem levou o crédito". Dessa forma, ainda que 
a assertiva ou formulação que deu base à construção do texto do autor $\mathrm{B}$, tenha sido originalmente trazida por $\mathrm{A}$, ao fazer esse tipo de citação, o autor $\mathrm{C}$ diminui indiretamente o impacto do trabalho do autor A.

Além dessas situações, Bordons e Zulueta (1999) citam também a salami science, ou seja, os cientistas fazem a fragmentação de um único trabalho completo em vários artigos menores (least publishable unit), buscando reconhecimento e melhores avaliações quanto a sua produtividade, ao mesmo tempo em que procuram justificar seus trabalhos perante as instituições onde atuam e às agências de fomento que os financiam. Ademais, as autoras apontam a existência da "autoria gratuita", pela qual o número de autores por artigo é maior do que a quantidade de pesquisadores que realmente contribuíram de alguma forma à pesquisa, e a chamada "síndrome do publicar ou perecer" (publish or perish syndrome), pela qual os cientistas, ao serem pressionados a publicar, desenvolvem um grande número de artigos, nem sempre de alta qualidade.

Em consequência a essa busca pela alta produtividade acadêmica, começaram a aparecer no mercado editorial os chamados predatory publishers, isto é, editoras "predatórias" que buscam lucrar sobre os cientistas, com promessas de publicação de artigos em um curto espaço de tempo. Segundo Bohannon (2013), o termo foi cunhado pelo bibliotecário Jeffrey Beall, da University of Colorado, que apresentou em sua página na internet uma lista com vários nomes de editoras que supostamente possuem práticas não-profissionais, cujos periódicos contam com corpos editoriais mal definidos e critérios escusos para a publicação dos artigos. A listagem de Beall, entretanto, gerou uma série de questionamentos na literatura, como os feitos por Diniz (2015), já que traz, em sua maioria, títulos de periódicos que são de acesso aberto e cujas sedes tem origem em países em desenvolvimento. A fim de testar o controle de qualidade dessas editoras, Bohannon (2013) se propôs a elaborar e submeter um artigo falso para 304 diferentes periódicos, dos quais 121 faziam parte da lista de Beall, 167 constavam do Directory of Open Access Journals (DOAJ), consagrado diretório que indexa periódicos de acesso aberto, e outras 16 revistas que apareciam nos dois locais.

De acordo com Bohannon (2013), apesar do mesmo conteúdo, os manuscritos tinham autorias e instituições de origem diferentes para cada periódico em que o artigo era submetido, sendo que essas variações nominais eram geradas aleatoriamente por um programa de computador. Além disso, para verificar a eficiência das suas revisões por pares, o artigo também continha falhas na metodologia, na descrição e apresentação dos dados e nas conclusões extraídas dos resultados. Erros tão graves para o autor, que qualquer revisor competente deveria facilmente poder identificá-los e, em vista disso, impedir a publicação do paper. Como resultado, Bohannon (2013) obteve retorno de 255 periódicos, sendo que o artigo foi aceito para publicação em 157 revistas e rejeitado pelas outras 98 . 0 autor destaca que o artigo foi aceito até mesmo por periódicos de grandes editoras, como Elsevier, Wolters Kluwer e Sage, e aponta que das 255 respostas que obteve, $60 \%$ parecem nem ter passado pela revisão por pares, isto é, foram aprovados ou rejeitados direto pelos editores responsáveis, fato que contraria o imperativo do ceticismo organizado discutido por Merton.

Para Hakan Arslan (apud BOHANNON, 2013, p.64), editor-chefe do European Journal of Chemistry, por exemplo, os resultados apresentados por Bohannon não apontam necessariamente para uma falha na revisão por pares, mas uma ruptura de confiança, já que espera-se que os artigos submetidos aos periódicos sejam originais e que todas as informações fornecidas estejam corretas. Outrossim, David Roos (apud BOHANNON, 2013, p.64), da University of Pennsylvania, acredita que se a investigação fosse realizada em periódicos de acesso restrito, baseados na subscrição da revista, o resultado seria o mesmo. A complexidade está no fato do 
acesso aberto dar margem para a multiplicação desses "periódicos de segunda classe". Para o pesquisador, "todos concordam que o acesso aberto é uma coisa boa. A questão é como alcançá-lo" (ROOS apud BOHANNON, 2013, p.64, tradução nossa).

Por fim, Gläser e Laudel (2007) concordam que, embora existam todas essas implicações, os indicadores bibliométricos e as análises baseadas em citação têm sido cada vez mais usadas pelos tomadores de decisão, posto que o processo requer menores custo e tempo dispendidos e apresentam menos possibilidades de serem feitos algum juízo de valor, uma vez que os resultados alcançados são mostrados através de gráficos e tabelas, o que facilita a visualização das informações. Em concordância com o conceito de capital científico de Bourdieu (2008), infere-se que a difusão de conhecimentos de modo mais amplo, proporcionado pelo acesso aberto, pode contribuir para uma obtenção maior desse capital simbólico por parte dos diversos atores do campo científico, tendo em vista que pode vir a atuar positivamente no impacto obtido pelos pesquisadores, centros de pesquisa e instituições de ensino.

\section{CONCLUSÃO}

O objetivo deste ensaio foi refletir sobre as mudanças que o acesso aberto trouxe à comunicação científica considerando as concepções propostas pelos autores dos Estudos Sociais de Ciência e Tecnologia. Nesse sentido, o acesso aberto mostra-se como um movimento muito próximo ao que foi proposto por Merton em seus imperativos institucionais, em especial ao comunismo e ao desinteresse, já que propõe um modelo de comunicação da ciência cujos resultados das pesquisas são livremente disponibilizados e estimula os cientistas a se moverem apenas pelo avanço da ciência e pela perspectiva de consequente crescimento da sua estima e reconhecimento dentro da academia.

Ao ampliar o acesso de cientistas com menor capital científico às publicações, o open access também apresenta potencial para influenciar o status quo da organização social da ciência. Em outras palavras, o acesso aberto permite que pesquisadores com menor prestígio tenham acesso a uma literatura já existente, mas que antes era disponibilizada somente através da sua aquisição ou via subscrição dos periódicos. Assim, ao terem a possibilidade de citar estes textos e agregarem mais aliados aos seus próprios trabalhos, conforme os conceitos apresentados por Latour, esses cientistas, ao publicarem e também disponibilizarem seus artigos em acesso aberto, poderão ter mais chances de serem reconhecidos e obterem futuras recompensas por suas contribuições.

Sobre esse último ponto, considerando que uma das justificativas da literatura para a existência da Open Access Citation Advantage é a de que os cientistas, em geral, disponibilizam em acesso aberto os seus melhores artigos (fazem o pagamento dos APCs, por exemplo), esses trabalhos, por serem de melhor qualidade, tendem a receber mais citações. Logo, é importante salientar que não é exatamente o acesso aberto que proporciona um maior número de citações a um artigo, mas a qualidade dele.

Por fim, através da realização do autoarquivamento de seus trabalhos ou do pagamento das taxas de processamento de artigos para publicação imediata de suas pesquisas em acesso aberto nos sites dos periódicos, os cientistas podem alterar a rígida hierarquia do campo científico descrito por Bourdieu. Isto é, as possíveis vantagens proporcionadas pelo acesso aberto no número de citações de uma publicação, advindos dos ganhos em visibilidade, legibilidade e acessibilidade desses artigos pelos pares, poderiam modificar as disparidades existentes entre os diferentes detentores de capital científico, ao impactar positivamente na avaliação desses pesquisadores junto às agências de fomento e instituições de ensino. 


\section{AGRADECIMENTOS}

À Fundação de Amparo à Pesquisa do Estado de São Paulo (FAPESP) processo no. 2015/16872-2.

\section{REFERÊNCIAS}

ANTELMAN, K. Do open-access articles have a greater research impact? College \& Research Libraries, v.65, n.5, p.372-382, set. 2004. Disponível em:

<https://doi.org/10.5860/crl.65.5.372> Acesso em: 08 abr. 2016.

ATCHINSON, A.; BULL, J. Will open access get me cited? an analysis of the efficacy of open access publishing in political science. PS: Political Science \& Politics, v.48, n.1, p.129-137, jan. 2015. Disponível em: <https://doi.org/10.1017/S1049096514001668> Acesso em: 20 ago. 2016.

BARNES, S. B.; DOLBY, R. G. A. The scientific ethos: a deviant viewpoint. European Journal of Sociology, v.11, n.1, p.3-25, 1970. Disponível em: <http://www.jstor.org/stable/23998697> Acesso em: 02 ago. 2017.

BÍBLIA. N. T. Mateus. In: BÍBLIA. Português. Bíblia Sagrada: Nova Versão Internacional. São Paulo: Editora Vida, 2000.

BOHANNON, J. Who's afraid of peer review? Science, v.342, n.6154, p.60-65, out. 2013. Disponível em: <http://science.sciencemag.org/content/342/6154/60> Acesso em: 26 out. 2016.

BORDONS, M.; ZULUETA, M. A. Evaluación de la actividad científica a través de indicadores biblimétricos. Revista Española de Cardiología, v.52, n.10, p.790-800, 1999. Disponível em: <http://www.revespcardiol.org/es/evaluacion-actividad-cientifica-travesindicadores/articulo/190/> Acesso em: 10 maio 2016.

BOURDIEU, P. Le champ scientifique: actes de la recherche en sciences sociales. Paris: Ed. du Seuil, 1976.

BOURDIEU, P. Os usos sociais da ciência: por uma sociologia clínica do campo científico. São Paulo: Editora UNESP, 2004.

BOURDIEU, P. Para uma sociologia da ciência. Lisboa: Edições 70, 2008.

BUDAPEST OPEN ACCESS INITIATIVE. 2002. Disponível em:

<http://www.budapestopenaccessinitiative.org/translations/portuguese-translation> Acesso em: 09 abr. 2016

CRAIG, I. D. et al. Do open access articles have greater citation impact? A critical review of the literature. Journal of Informetrics, v.1, n.3, p.239-248, 2007. Disponível em: <http://www.sciencedirect.com/science/article/pii/S1751157707000466> Acesso em: 05 abr. 2016.

CRISTOVÃO, H. T. Da comunicação informal a comunicação formal: identificação da frente de pesquisa através de filtros de qualidade. Ciência da Informação, Rio de Janeiro, v.8, n.1, p. 336, 1979. Disponível em: <http://revista.ibict.br/ciinf/article/view/135>Acesso em: 18 abr. 2016. 
DINIZ, E. Acesso aberto: um tema a ser mais bem explorado. RAE - Revista de Administração de Empresas, v.55, n.5, set./out. 2015. Disponível em: <http://rae.fgv.br/rae/vol55-num5-2015> Acesso em: 09 abr. 2016.

DROESCHER, F. D.; SILVA, E. L. 0 acesso aberto e o uso da informação científica. Investigación bibliotecológica, México, v.29, n.65, jan./abr. 2015. Disponível em: <http://www.revistas.unam.mx/index.php/ibi/article/view/54458> Acesso em: 18 abr. 2016.

FRANDSEN, T.F. The effects of open access on un-published documents: a case study of economics working papers. Journal of Informetrics, v.3, n.2, p.124-133, 2009. Disponível em: <http://www.sciencedirect.com/science/article/pii/S1751157708000746> Acesso em: 06 abr. 2016.

FREITAS, M. H. de A. Oito anos de Transinformação. Transinformação, v.9, n.3, p.120-134, set./dez. 1997. Disponível em: <http://periodicos.puc-

campinas.edu.br/seer/index.php/transinfo/article/view/1580 > Acesso em: 10 maio 2016.

GLÄSER, J.; LAUDEL, G. The social construction of bibliometric evaluation. In: WHITLEY, R.; GLÄSER, J. The changing governance of the sciences: the advent of research evaluation systems. Dordrecht, Springer, 2007.

GODIN, B. The linear model of innovation: the historical construction of an analytical framework. Science, Technology \& Human Values, v.31, n.6, p.639-667, 2006. Disponível em: <http://journals.sagepub.com/doi/abs/10.1177/0162243906291865> Acesso em: 31 jul. 2017.

GUMIEIRO, K. A.; COSTA, M. de S. 0 uso de modelos de negócios por editoras de periódicos científicos eletrônicos de acesso aberto. Perspectivas em Ciência da Informação, Belo Horizonte, v.17, n.4, p. 100-122, out./dez. 2012. Disponível em:

<http://portaldeperiodicos.eci.ufmg.br/index.php/pci/article/view/1489> Acesso em: 10 abr. 2016.

HARNAD, S. OA impact advantage = EA + (AA) + (QB) + QA + (CA) + UA. School of Electronics \& Computer Science, University of Southampton, 2005. Disponível em: <http://eprints.soton.ac.uk/262085/> Acesso em: 21 abr. 2016.

HARNAD, S. Opening access by overcoming Zeno's Paralysis. In: JACOBS, N. (ed.) Open Access: key strategic, technical and economic aspects. Oxford: Chandos Publishing Limited, 2006.

HARNAD, S.; BRODY, T. Comparing the impact of open access (OA) vs. non-OA articles in the same journals. D-Lib Magazine, v.10, n.6, jun. 2004. Disponível em:

<http://www.dlib.org/dlib/june04/harnad/06harnad.html> Acesso em: 15 jul. 2016.

KURAMOTO, H. Informação científica: proposta de um novo modelo para o Brasil. Ciência da Informação, v.35, n.2, p.91-102, maio/ago. 2006. Disponível em:

<http://revista.ibict.br/ciinf/article/view/1144> Acesso em: 18 jun. 2016.

LATOUR, B. Ciência em ação: como seguir cientistas e engenheiros sociedade afora. Tradução de Ivone C. Benedetti. 2. ed. São Paulo: Editora UNESP, 2011.

LATOUR, B.; WOOLGAR, S. A vida de laboratório: a produção dos fatos científicos. Rio de Janeiro: Relume Dumará, 1997.

LAWRENCE, S. Free online availability substantially increases a paper's impact. Nature, 2001. Disponível em: <http://www.nature.com/nature/debates/e access/Articles/lawrence.html> Acesso em: 21 abr. 2016. 
LIMA, R. A. de; VELHO, L. M. L. S.; FARIA, L. I. L. de Bibliometria e "avaliação" da atividade científica: um estudo sobre o índice h. Perspectivas em Ciência da Informação, v.17, n.3, p.3-17, jul./set. 2012. Disponível em:

<http://portaldeperiodicos.eci.ufmg.br/index.php/pci/article/view/1139> Acesso em: 08 ago. 2016.

MEADOWS, A. J. Comunicação científica. Brasília: Briquet de Lemos Livros, 1999.

MERTON, R. K. The Matthew effect in science: the reward and communication systems of science are considered. Science, v.159, p.56-63, jan. 1968. Disponível em:

<http://science.sciencemag.org/content/159/3810/56> Acesso em: 10 abr. 2016.

MERTON, R. K. "La estrutura normativa de la ciencia”. In: MERTON, R. K.. La Sociologia de la ciência 2. Madrid: Alianza Editorial, 1997.

MOREIRA, M. L.; VELHO, L. Pós-graduação no Brasil: da concepção “ofertista linear" para "novos modos de produção do conhecimento" implicações para avaliação. Avaliação, Campinas, v.13, n.3, p.625-645, nov. 2008. Disponível em:

<http://www.scielo.br/pdf/aval/v13n3/02.pdf> Acesso em: 28 set. 2015.

MUELLER, S. P. M. O círculo vicioso que prende os periódicos nacionais. DataDramaZero Revista de Ciência da Informação, v.0, dez. 1999. Disponível em:

<http://eprints.rclis.org/6189/1/Art_04.htm> Acesso em: 03 ago. 2017.

MUELLER, S. P. M. A comunicação científica e o movimento de acesso livre ao conhecimento. Ciência da Informação, Brasília, v.35, n.2, p.27-38, maio/ago. 2006. Disponível em: <http://revista.ibict.br/ciinf/article/view/1138> Acesso em: 18 jun. 2016.

PINFIELD, S.; SALTER, J.; BATH, P. A. The "total cost of publication" in a hybrid open-access environment: institutional approaches to funding journal article-processing charges in combination with subscriptions. Journal of the Association for Information Science and Technology, 2015. Disponível em: <http://dx.doi.org/10.1002/asi.23446> Acesso em: 10 maio 2016.

PRIEM, J.; GROTH, P.; TARABORELLI, D. The altmetrics collection. PLOS ONE, v.7, n.11, nov. 2012. Disponível em: <https://doi.org/10.1371/journal.pone.0048753> Acesso em: 10 abr. 2016.

RODRIGUES, E. Acesso Livre ao conhecimento: a mudança do sistema de comunicação da ciência e os profissionais de informação. Cadernos BAD, n.1, p.24-35, 2004. Disponível em: <https://www.bad.pt/publicacoes/index.php/cadernos/article/view/836> Acesso em: 10 maio 2016.

RODRIGUES, M. P. L. Citações nas dissertações de mestrado em Ciência da Informação. Ciência da Informação, Brasília, v.11, n.1, p.35-61, 1982. Disponível em: <http://revista.ibict.br/ciinf/article/view/177> Acesso em: 03 ago. 2017.

ROSENBERG, N. Por dentro da caixa preta - tecnologia e economia. Campinas: Editora da Unicamp, 2006.

SISMONDO, S. An introduction to science and technology studies. Chichester, Reino Unido: Wiley-Blackwell, 2011.

SPIEGEL-RÖSING, I. The study of Science, Technology and Society (SSTS): recents trends and future challenges. In: SPIEGEL-RÖSING, I.; SOLLA PRICE, D. (eds.) Science, Technology and Society. London and Beverly Hills: International Council for Science Policy Studies, Sage Publications, 1977. 
STOKES, D. E. 0 Quadrante de Pasteur - a ciência básica e a inovação tecnológica. Campinas: Editora da Unicamp, 2005.

SUBER, P. Open access. Cambrigde: MIT Press essential knowledge, 2012.

SWAN, A. The Open Access citation advantage: studies and results to date. Technical Report, School of Electronics \& Computer Science, University of Southampton. 2010. Disponível em: <http://eprints.ecs.soton.ac.uk/18516/> Acesso em: 02 mai. 2015.

TZOC, E. El acceso abierto en América Latina: situación actual y expectativas. Revista Interamericana de Bibliotecología, v.35, n.1, p.83-95, 2012. Disponível em: <http://eprints.rclis.org/19991/1/v35n1a8.pdf> Acesso em; 02 ago. 2017.

VAN RAAN, A. F. J. Bibliometrics and internet: some observation and expectations. Scientometrics, v.50, n.1, p.59-63, 2001. Disponível em: <https://link.springer.com/article/10.1023/A\%3A1005690102069> Acesso em: 07 abr. 2016.

VESSURI, H. Perspectivas recientes en el Estudio Social de la Ciencia. Interciencia, v.16, n.2, mar./abr., p. 60-68, 1991. Disponível em: <ftp://ftp.ige.unicamp.br/pub/CT010/aula\%201/Vessuri(1991).pdf> Acesso em: 20 jun. 2017.

WEITZEL, S. R. As novas configurações do Acesso Aberto: desafios e propostas. Revista Eletrônica de Comunicação, Informação \& Inovação em Saúde, v.8, n.2, p.65-75, jun. 2014. Disponível em: <http://www.arca.fiocruz.br/bitstream/icict/17101/2/2.pdf> Acesso em: 28 jul. 2017. 